\section{Microwaved Bacterial Cellulose-Based Hydrogel Microparticles for the Healing of Partial Thickness} Burn Wounds

Manisha Pandey ${ }^{1,2}$, Najwa Mohamad², Wan-Li Low ${ }^{3}$, Claire Martin³, Mohd Cairul Iqbal Mohd Amin²

${ }^{1}$ School of Pharmacy, International Medical University, Kuala Lumpur, Malaysia

${ }^{2}$ Centre for Drug Delivery Research, Faculty of Pharmacy, Universiti Kebangsaan Malaysia, Jalan Raja Muda Abdul Aziz, 50300, Kuala Lumpur, Malaysia

${ }^{3}$ School of Pharmacy, Faculty of Science and Engineering, University of Wolverhampton, Wulfruna Street, Wolverhampton, WV1 1LY, UK

\section{*Corresponding author}

Prof. (Dr.) Mohd Cairul Iqbal Mohd Amin (PhD)*

Centre for Drug Delivery Research,

Faculty of Pharmacy, Universiti Kebangsaan Malaysia

Jalan Raja Muda Abdul Aziz 50300, Kuala Lumpur, Malaysia

Tel: +60392897690

Fax: +60326983271

Email: mciamin@ukm.edu.my 


\begin{abstract}
Burn wound management is a complex process because the damage may extend as far as the dermis which has an acknowledged slow rate of regeneration. This study investigates the feasibility of using hydrogel microparticles composed of bacterial cellulose and polyacrylamide as a dressing material for coverage of partial-thickness burn wounds. The microparticulate carrier structure and surface morphology was investigated by Fourier transform infrared, X-ray diffraction, elemental analysis, and scanning electron microscopy. The cytotoxicity profile of the microparticles showed cytocompatibility with L929 cells. Dermal irritation test demonstrated that the hydrogel was non-irritant to the skin and had a significant effect on wound contraction compared to the untreated group. Moreover, histological examination of in vivo burn healing samples revealed that the hydrogel-treatment enhanced epithelialization and accelerated fibroblast proliferation with wound repair and intact skin achieved by the end of the study. Both the in vitro and in vivo results proved the biocompatibility and efficacy of hydrogel microparticles as a wound dressing material.
\end{abstract}

Keywords: Hydrogel microparticles, Bacterial cellulose, Cytotoxicity, Partial thickness burn wound, Microwave irradiation 


\section{INTRODUCTION}

Globally, burns are one of the most serious problems in public health according to the World Health Organization (WHO). The National Centre for Injury Prevention and Control in the United States stated that approximately 2 million fires are reported each year which result in 1.2 million people with burn injuries. Moderate to severe burn injuries requiring hospitalization account for approximately 100,000 of these cases, and about 5,000 patients die each year from burn-related complication [1]. Skin burns are primarily caused by heat, electricity, chemicals or radiation [2]. According to healthcare professionals, partial- and full-thickness burn wounds are complex to manage because the damage extends to the dermis, and the regeneration process is slow owing to fewer viable epidermal cells [3-4]. Currently, the primary goal for healthcare professionals is to accelerate the wound healing process by using an appropriate wound dressing.

Bacterial cellulose (BC) is an attractive biomaterial for wound dressing applications as it can provide a moist environment for the wound, hence enhancing the healing process. Various studies have shown the effectiveness of BC-based wound healing materials. For instance, bacterial cellulose-chitosan (BC-Ch) membranes applied to wounds as a dressing material revealed significant epithelialization and regeneration of the skin, faster than those treated with BC or even a commercial wound dressing product Tegaderm ${ }^{\text {TM }}$ [5]. Similarly, a bacterial cellulose membrane produced from Acetobacter sp. A10 isolated from decaying apple, showed greater acceleration of the wound healing process in a burn model through the regulation of angiogenesis and connective tissue formation [6].

Natural polymers are frequently used in the synthesis of hydrogel wound dressing for burns because of their similarity to the extracellular matrix, biodegradability, and biocompatibility. These commonly occurring natural polymers include glucans, dextrans, cellulose, alginic acid, hyaluronic acid, chitin, chitosan, heparin, chondroitin, dermatan sulfate, and keratan sulfate [2,7]. Among these natural polymers, BC obtained from Acetobacter, Sarcina ventriculi and Agrobacterium genera, have the greatest potential to be used as wound dressings and/or artificial skin. The mechanical strength, high water retention, and biocompatibility of BC encourage its use as a temporary skin substitute, wound dressing material [8,9], and for vascular implant applications [10]. These natural product-based polymers are commonly cross-linked with synthetic polymeric materials. The reasons are to ensure that the resulting hydrogel can entrap water to prevent dissolution of the hydrophilic polymer chains in an aqueous environment, and to provide structural stability. Numerous physical and chemical approaches have been used in order to synthesize hydrogels: Physically crosslinked hydrogels include ionic interactions, crystallization, crosslinking by amphiphilic block and graft copolymers, proteins as well as hydrogen bond interactions. Conversely, chemically crosslinked hydrogels can be synthesized by radical polymerization, chemical reaction of complementary groups, high-energy irradiation and crosslinking using enzymatic reactions [11]. However, the use of accelerated microwave irradiation is gaining attention because of its relatively low energy consumption and production costs as well as excellent safety profile [12, 13].

In our previous study, a hydrogel of $\mathrm{BC}$ combined with acrylamide was synthesized by microwave irradiation using different solvent ratios to dissolve the BC, and a preliminary safety assessment performed. The results revealed that the fabricated hydrogel was highly porous (80.3 to $255 \mu \mathrm{m})$ and had a high swelling ratio [14]. A highly macroporous structure facilitates exudate absorption and moisture preservation in the area 
surrounding the wound. Therefore, the aim of this study was to investigate the physical properties and cytotoxicity of these optimized hydrogels as wound dressings. Furthermore, the effects of BC/AM hydrogel microparticles on skin irritation and the wound-healing process for a partial thickness burn wound were also evaluated in a rat model.

\section{MATERIALS AND METHODS}

Materials

The bacterial cellulose (BC) was isolated from nata de coco and further purified, lyophilized, characterized, and identified as described in the British Pharmacopoeia (2010). Acrylamide, potassium persulfate (KPS), and $N, N^{\prime}-$ methylenebisacrylamide (MBA) were supplied by Sigma-Aldrich (St. Louis, MO, USA). The L929 (mouse fibroblast) cell line was purchased from the American Type Culture Collection (ATCC, Rockville, MD, USA) and cultured in advanced minimum essential medium (MEM) with $110 \mathrm{mg} / \mathrm{L}$ sodium pyruvate, non-essential amino acids without L-glutamine (Gibco ${ }^{\mathrm{TM}}$ Life Technologies, USA), $10 \%$ fetal bovine serum (FBS, Sigma), and $1 \%$ penicillin/streptomycin (Thermo-Fisher Scientific, USA). The alamarBlue ${ }^{\circledR}$ was purchased from Invitrogen (Carlsbad, CA, USA) for the cell viability assay. The female Sprague-Dawley rats used in this study were purchased from the Laboratory Animal Centre of the Universiti Kebangsaan Malaysia.

The animals were housed in a controlled environment at a temperature of $20-22^{\circ} \mathrm{C}$, relative humidity of $50-60 \%$, and under 12-h light-dark cycles. The animals were allowed free access to food and water, and quarantined for 1 week before treatment.

BC/AM hydrogel microparticles preparation

Firstly, microfine BC powder was obtained from the nata de coco using our previously reported method [15, 16]. The microfine $\mathrm{BC}$ powder was dissolved in a $\mathrm{NaOH}(8 \% \mathrm{w} / \mathrm{v})$ and urea $(4 \% \mathrm{w} / \mathrm{v})$ solvent system to obtain the $\mathrm{BC}$ solution, according to the method described by Pandey et al. (2014) [14]. Subsequently, the acrylamide (1.5M) was added to $20 \mathrm{~mL}$ of BC solution followed by the addition of KPS $\left(7.4 \times 10^{-4}\right.$ moles $)$ as the initiator and MBA (0.00129 mole) as the crosslinker. The resultant mixture was irradiated using a microwave irradiator (MS2388K, LG Electronics, Seoul, South Korea) at $340 \mathrm{~W}$ of power for $40 \mathrm{~s}$ to synthesize the hydrogels. The prepared hydrogels were soaked in distilled water for $120 \mathrm{~h}$ to remove the unreacted monomers and dried in an oven for 24 $\mathrm{h}$ at $60^{\circ} \mathrm{C}$.

After extraction, the hydrogel was freeze-dried using a benchtop freeze dryer (ScanVac Cool Safe, 1104). The freeze-dried hydrogel was micronized using a pulverizer (Pulverisette 14, Frisch, Germany) and then sieved to produce hydrogel microparticles with a particle size in the range of $50-150 \mu \mathrm{m}$.

Characterization of hydrogel microparticles

The prepared hydrogel microparticles were characterized using a Fourier transform infrared (FT-IR) Spectra 2000 (Perkin Elmer, Waltham, MA, USA) using the potassium bromide (KBr) disk method over the range of 4000$400 \mathrm{~cm}^{-1}$ and X-ray diffractograms were recorded using an X-ray diffractometer (D8-Advance, Bruker AXS, Germany) with CuKó radiation at $40 \mathrm{kV}$ and $50 \mathrm{~mA}$ in the differential angle range of 5-60 $(2 \theta)$. The elemental 
analyses of the microparticles were performed using energy dispersive X-ray spectrometer (INCA 300X-sight, hydrogen, and nitrogen content. The particle sizes of the hydrogel microparticles were studied using an optical microscope (Olympus, Fluoview FV 1000) and a digital camera (Olympus optical, U-TV1X-2, Japan). The diameters of 90 microparticles $(n=3)$ were measured using image analysis (Olympus soft imaging solution). Hydrogel microparticles were soaked in water for $24 \mathrm{hrs}$, then dried in the freeze dryer and oven to observer the effect of drying methodology on surface morphology. The porous structures of the freeze-dried and oven dried BC/AM hydrogels microparticles were observed by scanning electron microscopy (SEM, LEO 1450 VP, Oberkochem-Zeiss, Germany). Samples were mounted on an aluminum stub, and coated with gold in a sputter coater (SC500, BioRad, London, UK) under an argon atmosphere.

Determination of swelling behavior of microparticles

The swelling behavior of the microparticles was studied in PBS at pH values of 1.5, 5, and 7.4. The hydrogel microparticles $(10 \mathrm{mg}$ ) were suspended in $2 \mathrm{~mL}$ of buffer solution in a pre-weighed micro-centrifuge tube. At predetermined time intervals, excess buffer solution was carefully removed, and the weight of the swollen particles was determined. The swelling ratio (SR) for each sample was calculated as follows:

$S R(\%)=\frac{\mathrm{Gs}-\mathrm{Gd}}{\mathrm{Gd}} \times 100$

Where $G_{d}$ and $G_{s}$ are the weight of the dry and swollen particles, respectively.

Cytocompatibility study

Cell viability study

The cell viability study was performed in the L929 (mouse fibroblast) cell line using both direct contact and extraction methods with alamarBlue ${ }^{\circledR}$. The cell line was cultured in advanced MEM containing $110 \mathrm{mg} / \mathrm{L}$ sodium pyruvate and non-essential amino acids without L-glutamine, supplemented with $10 \%$ fetal bovine serum and $1 \%$ penicillin/streptomycin. The cultures were maintained at $37^{\circ} \mathrm{C}$ in a humidified atmosphere of $5 \% \mathrm{CO}_{2} / 95 \%$ air. Prior to the study, hydrogel samples were sterilized using an autoclave.

The cultured cells maintained in the advanced MEM were seeded in 96-well culture plates at $3 \times 10^{4}$ cells per well and incubated for $24 \mathrm{~h}$. In the extraction method, the hydrogel microparticles were incubated with culture medium for $48 \mathrm{~h}$ at a concentration of $4.0 \mathrm{mg} / \mathrm{mL}$. The culture medium $(100 \mu \mathrm{L})$ containing the extract of the hydrogel microparticles was transferred to 96-well plates and the cells were incubated for an additional 24 and 48 $\mathrm{h}$ at $37^{\circ} \mathrm{C}$ in a $5 \% \mathrm{CO}_{2} / 95 \%$ air atmosphere. For the direct method, the cells were seeded in 24 -well plates at an initial cell density of $5 \times 10^{4}$ and incubated for $24 \mathrm{~h}$. The hydrogel microparticles were added to the 24 -well plates after incubation and further incubated for 24 and 48 h. Following incubation, $20 \mu \mathrm{L}$ of the alamarBlue ${ }^{\circledR}$ reagent was added to the treated cells followed by a 4-h incubation prior to analysis [17]. The absorbance of each sample was measured using a microplate reader (Varioskan Flash, Thermo Scientific, Waltham, MA, USA) at $570 \mathrm{~nm}$ (A570) and the cell viability was calculated using the following equation: 
Cell viability $(\%)=\frac{\mathrm{A} 570 \text { of treated cells }}{\mathrm{A} 570 \text { of control cells }} \times 100$

All the experiments were run in triplicate.

\section{Live/Dead assay}

The cytotoxicity of the hydrogel microparticles was qualitatively assessed using a LIVE/DEAD® viability/cytotoxicity kit (Life Technologies, USA). Firstly, the cells were treated with the hydrogel microparticles for $24 \mathrm{~h}$ in a 96-well plate and rinsed with PBS. Then, the cells were stained with fluorescent dye $(1 \mu \mathrm{M}$ calcein $\mathrm{AM}$ and $2 \mu \mathrm{M}$ ethidium homodimer-1 (EthD-1) per well) and incubated for $1 \mathrm{~h}$ at $37^{\circ} \mathrm{C}$ and $5 \% \mathrm{CO}_{2}$ atmospheric conditions. Finally, the cells were washed thrice with PBS and observed using a Floid cell imaging station.

Animal studies

The burn wound healing characteristics of the hydrogel microparticles were evaluated in Female Sprague-Dawley rats $(\mathrm{n}=54)$ weighing 150-200 g. All the experimental protocols were approved by the Universiti Kebangsaan Malaysia Animal Ethics Committee (UKMAEC) prior to the study. The rats were given free access to a standard pellet diet, water ad libitum, and maintained under a 12-h light/12-h dark cycle. For the animal study, the hydrogel microparticles were prepared as amorphous gel by soaking them in sterilized water, and then stirred for 5 min using a mechanical stirrer. Prior to the application, the gel was sterilized using an autoclave.

\section{Dermal irritation tests}

Four Sprague-Dawley rats per group were used for the skin irritation test (test and negative control groups). The dorsal areas of the rats $\left(\sim 5 \mathrm{~cm}^{2}\right)$ were shaved with an electric razor. After $24 \mathrm{~h}$, the shaved area of the test group was treated with the amorphous hydrogel and covered with gauze while the negative control group remained untreated. The skin reactions including erythema and edema were evaluated at 1, 4, 24, and $48 \mathrm{~h}$ respectively.

\section{Establishment of skin burns}

Each rat was anesthetized with isoflurane, and the dorsal area was shaved and disinfected with $70 \%$ alcohol. Subsequently, a 1-cm diameter stainless steel template was heated in boiling water for 5 min and then applied to the shaved area for 10s to produce partial thickness skin burns [18].

\section{Treatment of burn wounds}

The rats were divided into three groups ( $\mathrm{n}=18$ per group): test, treated with amorphous hydrogel; positive control, treated with Intrasite gel; and negative control, untreated. Shortly after induction, the wounds were rinsed with $70 \%$ alcohol and the treatments were applied. The wounds were treated once every day, after rinsing with an alcohol swab. After positioning the dressings, they were secured with bandages and universal surgical tape. 


\section{Visual observation of burn wounds}

Wound closure was measured at regular time intervals, to calculate the percentage of wound closure and epithelialization. Standardized digital photographs of the wounds were taken at day 1, 3, 7, and 14 before replacement of the dressings and the wound closure was measured by marking the wound area on a transparent polyethylene sheet. Further, the marked wound area on the sheet was calculated using graph paper. The wound closure (\%) was calculated using the formula below [19]:

Wound closure $(\%)=\frac{A 0-A t}{A 0} \times 100$

Where $A_{o}$ is the original burn wound area and $A_{t}$ is the burn wound area at the time of observation. The wounds were considered completely healed once the macroscopic scabs had been shed, and the epidermal layer had formed.

\section{Histological analysis}

The animals were euthanized on day 1, 7, and 14. The excised burn sites were then treated with formaldehyde $(10 \%)$, embedded in paraffin, and cut into $4-\mu \mathrm{m}$ thick sections using a cryomicrotome (Leica RM 2145, Germany). The tissue sections were dewaxed, rehydrated, and stained with hematoxylin and eosin (H\&E) and Masson's trichrome stain, and then examined using an optical microscope under 20 and 40× magnification.

Statistical analysis

All data are in triplicates and presented as the mean \pm standard deviation (SD). The statistical analysis was carried out using the IBM statistics for the social sciences (SPSS) software version 21, USA.

\section{RESULTS AND DISCUSSION}

Characterization of hydrogel microparticles

The FT-IR spectra of the pure BC and hydrogel microparticles are shown in Figure 1a. The spectra of BC shows characteristic peaks at $1163,1059,3398$, and $2914 \mathrm{~cm}^{-1}$, which corresponded to C-O-C stretching of the ether linkage (1,4- $\beta$-D-glucoside), C-O stretching vibration, O-H stretching of the intermolecular hydrogen bonds, and C-H stretching, respectively. Similarly, spectra of polyacrylamide exhibited characteristic peaks representing $\mathrm{C}=\mathrm{O}$ stretching of the amide $\mathrm{I}$ band, asymmetric and symmetric stretching vibrations of the $\mathrm{N}-\mathrm{H}$ group, and $\mathrm{C}-\mathrm{N}$ stretching at $1658,3421,3215$, and $1451 \mathrm{~cm}^{-1}$, respectively [14, 20, 21]. However, the spectra of the hydrogel microparticles confirmed the grafting of polyacrylamide onto BC by the presence of peaks at 3438 and $2924 \mathrm{~cm}^{-1}$ which represent the overlapping of the $\mathrm{O}-\mathrm{H}$ group of $\mathrm{BC}$ with the $\mathrm{N}-\mathrm{H}$ group of polyacrylamide and the $\mathrm{C}-\mathrm{H}$ groups of BC and polyacrylamide, respectively. The appearance of peaks at 1568 and $1408 \mathrm{~cm}^{-1}$ assigned to the asymmetric and symmetric stretching of the carboxylate anion, respectively, indicates the partial hydrolysis of polyacrylamide $[22,23]$. The structural elucidation of the microparticles was conducted by using carbon-13 $\left({ }^{13} \mathrm{C}\right)$ solid-state nuclear magnetic resonance (NMR) as reported by Pandey et al. (2014), which revealed the 
polymerization of acrylamide along with the grafting of BC (Figure 1b) [14]. On the other hand, the X-ray incorporation of bulkier groups in the network or a decrease in intermolecular hydrogen bonding (Figure 1c). A similar pattern was observed by Kumar et al. 2009 [24] and Sutar et al. 2008 [25] with the grafting of a natural polymer with polyacrylamide.

The elemental analysis was also performed for the hydrogel microparticles. It is well established that there is no nitrogen $(\mathrm{N})$ molecule in $\mathrm{BC}$. The significant value of $\mathrm{N}$ in the microparticles confirms the grafting of acrylamide on BC (Figure 2). This result was in agreement with the observation reported by Vijan et al. 2012 [26].

The particle size of the hydrogel microparticles was $92.58 \pm 24.5 \mu \mathrm{m}$. The size of the dried microparticles was also confirmed by SEM analysis, and the average diameter was $106.02 \pm 32.73$, which was in agreement with the previous results. Figure $3 \mathrm{a}$ and $\mathrm{b}$ illustrate the surface morphology of oven-dried and freeze-dried swollen microparticles. It was evident from the illustration that the size of the freeze-dried swollen microparticles was larger than that of the oven-dried microparticles. The result also reveals the effect of the drying process on surface morphology. For instance, the oven-dried microparticles (Figure 3a) appeared to be more compact, dense, relatively smaller, and smoother than the microparticles obtained via freeze-drying (Figure $3 b$ ). The porous structure of the particles was apparent with the freeze-dried microparticles (Figure 3c).

Swelling study

Swelling studies were conducted to measure the water uptake capacity of the hydrogel microparticles at $\mathrm{pH} 1.5$, 5, and 7.4. The swelling ratio of the microparticles was more than $2000 \%$ in the first hour of the study and reached maximum swelling after $8 \mathrm{~h}$ at $3066 \%$ at $\mathrm{pH}$ 7.4. This was due to the larger surface area of the hydrogel microparticles compared to that of the hydrogel disc. The hydrogel microparticles also showed pH sensitivity with the least absorption occurring at the acidic $\mathrm{pH}$, but the swelling ratio also increased drastically with increasing $\mathrm{pH}$. At basic $\mathrm{pH}$, the strong repulsive forces created between the ionized carboxylate groups (COO-) were the main contributing factor for the higher swelling values attained by the microparticles (Figure 4a). These carboxylate groups (COO-) were generated by the partial hydrolysis of polyacrylamide in the presence of $\mathrm{NaOH}$. A similar phenomenon was observed by Ibrahim et al. 2011 [27] who synthesized biodegradable pH-responsive alginate-poly (lactic-co-glycolic acid) nano/micro hydrogel matrices for the oral delivery of silymarin. They found that the microparticles showed maximum swelling at $\mathrm{pH}$ 7.4. This behavior can be attributed to the fact that at $\mathrm{pH}$ 7.4, most of the free carboxylic groups of alginate would be ionized.

Cell viability study

The in vitro cytotoxicity test is the first step in evaluating the biocompatibility of polymers intended for use as drug carriers. The International Organization for Standardization (ISO-10993) has specified various cytotoxicity evaluations for medical devices and materials based on various endpoints including cell number, morphology, and cellular activity. L929 cells are the most widely used cells in cytotoxicity test because of its advantages like easy to store, breed rapidly, easy to culture and subculture in vitro. It was recommended by the American Society for Quality Control as the standard cell line in the cytotoxicity test [28]. The cytotoxicity of the hydrogel was 
evaluated by using the extract dilution (indirect contact) and direct contact methods, as recommended by the ISO guidelines.

A viability assay (indirect and direct method) in fibroblast cells, revealed that cell viability was more than $85 \%$ at 24 and $48 \mathrm{~h}$ with both the methods (Figure 4b). In the case of both methods, the possible cause of cell death was due to slight changes in $\mathrm{pH}$ or the extended period of incubation. A comparison between the direct and extraction methods showed a significant difference $(\mathrm{P}<0.05)$ in cell viability. The extraction method has higher cell viability in comparison to the direct contact method due to presence of swollen hydrogel microparticles. These swollen microparticles caused physical trauma to the cultured cells by either exerting pressure via movement or by crushing due to weight [29]. Non-penetrating trauma or blunt force trauma refers to physical trauma which was exerted by the swollen hydrogel on the cells. Previous studies have indicated that wound dressings can be considered non-toxic and acceptable for wound application if the cell viability is greater than $85 \%$ [5].

The results of the live/dead assay are in agreement with that of the in vitro cytotoxicity tests since no significant difference was observed in the cell morphology and viability of both the 24 - and $48 \mathrm{~h}$ microparticlestreated cells compared to the control group (Figure 5). The majority of cells treated with the microparticles exhibited green fluorescence, which indicated live cells and demonstrated that the microparticles were non-toxic and did not affect the metabolic activity of the L929 cells.

Animal studies

The superior characteristics of the BC have made it useful for a number of diverse applications especially in the biomedical field because of its good biocompatibility. For instance, BC may be used as a scaffold for tissue engineering and in wound dressings for burn or wound repair [8, 9]. Furthermore, in a recent skin compatibility study, it was demonstrated that BC membranes did not cause adverse reactions in the skin and when loaded with a small percentage of glycerol, they also provided a beneficial moisturizing effect [30]. Similarly, Kwak et al. 2015 [6] and Muangman et al. 2011 [31] investigated the effectiveness of bacterial cellulose membranes in burn wound healing. They found that bacterial cellulose membranes/pellicles can accelerate the burn wound healing process without showing any sign of skin irritation and/or allergy. However, restricted swelling and stability limits the application of pure bacterial cellulose, but this has been improved by grafting with other polymers as reported by Lin et al. 2013 [5] and Cai \& Kim 2010 [32]. They grafted the bacterial cellulose film with natural polymers and reported that the BC composite has more thermal stability and biocompatibility than pure BC. Likewise, in our previous study, BC/AM composite showed better thermal stability and biocompatibility [14, 21] and also exhibited higher swelling properties than pure $\mathrm{BC}$ at basic $\mathrm{pH}$, as the wound exudate is also basic in nature.

In this study, the hydrogel microparticles of BC were grafted with polyacrylamide and had a high water uptake capacity, porous structure, and were non-toxic to L929 cells. These hydrogel microparticles can easily be prepared by a microwave irradiation method and can be stored in a dry condition, which is structurally more stable and can be converted into amorphous hydrogel when required by soaking in sterilized water. These properties make it a suitable potential material for burn wound dressings. As a result, the hydrogel microparticles were explored for the potential to heal wounds, using an in vivo rat model. 


\section{Skin irritation tests}

Skin irritation safety testing and risk assessment for a new product and the ingredients it contains is a critical requirement before it can be introduced to the market. The substance to be tested is applied as a single dose to the skin of an experimental animal and untreated skin areas of the test animal serve as the negative control. The test substance should be applied to a small area of skin and covered with a gauze patch, which is held in place with non-irritating tape.

After application of the hydrogel on the shaved area of the rats, no signs of skin irritation (erythema or edema) were observed at 1, 4, 24, and $48 \mathrm{~h}$. Therefore, the results revealed that the hydrogel is safe and can be used as dressing material since it did not show any sign of causing skin irritation. This is in agreement with previous reports that both polymers (BC and polyacrylamide) present as constituents of the hydrogels are biocompatible [30, 33].

\section{Macroscopic observations}

The healing patterns of the wounds were observed at day 1, 3, 7, and 14 after wound creation and are shown in Figure 6. The redness and swelling, which is a sign of inflammation [34] was observed on day 1 and 3 for all three groups. Moreover, infection and wound size reduction was also not reported during the initial 3 days. Significant differences were noted in the changes between the untreated and hydrogel-treated groups at day 7 post-wounding. The hemorrhagic-scabbed wounds were observed in the untreated group while the positive control and hydrogeltreated groups showed no hemorrhaging at the wound sites. Additionally, narrowing of the wound area was faster in the hydrogel-treated and positive control groups than that in the untreated group. On day 14 post wounding, the hydrogel-treated and positive control groups showed regenerated skin that was formed from the burned skin, which indicated that the scars were almost completely healed. In contrast, the wound recovery of the negative control group was significantly delayed. The fast healing of the hydrogel-treated group may be attributed to the moist environment, which accelerated the epithelialization process by supporting the migration of epithelial cells to the wet area of the wound [35].

\section{Wound closure rate}

The rate of contraction of the wound was estimated by determining the unclosed wound area as a function of time (Figure 7). Compared with the untreated control, the hydrogel-treated and positive control groups showed no significant difference $(\mathrm{P}>0.05)$ in wound closure rate on day 1 and 3 . Wound closure rates of 55\% and 52\% were achieved by day 7 in the hydrogel-treated and positive control groups, respectively, and there was no significant difference between these groups. In contrast, the untreated group healed slowly and only $28 \%$ wound closure rates were achieved in 7 days. On day 14, the wound contraction had attained 80\%, which was $14 \%$ higher than that of the untreated group. These results are in agreement with the macroscopic observation, which showed that the crusts were formed and shed much earlier than that in the untreated group. Similar findings were observed in our previous study, in which burn wounds were treated with a hydrogel sheet composed of BC and acrylic acid [36]. 


\section{Microscopic observation}

The histopathological examination was performed on the burn wound to observe the healing pattern on day 1,7 , and 14 post-burn induction using H\&E staining (Figure 8a) and Masson's trichrome staining (Figure 8b) in all three groups. In the early stages of healing, it was difficult to assess the difference between the untreated and treated groups. On day 1, the ulceration area, which was covered with inflammatory cells (neutrophils) and a thick layer of necrotic tissue primarily composed of dead tissue, was observed in all the groups. Numerous neutrophil infiltrated the wound area along with a few lymphocytes and macrophages, which are responsible for the engulfment of microorganisms or pathogens present in the wound area [37]. Masson's trichrome staining on day 1 showed damaged collagen fibers along with destroyed epidermis.

An extensive ulcerative area of the epidermis was apparent in both the treated and untreated groups on day 7 post-burn induction. Scab formation was observed in the untreated group in the epidermis layer along with necrosis of the dermis and subcutaneous tissue that had been replaced by granulation tissue. Moreover, reepithelialization was also observed in the untreated group. In contrast, the hydrogel-treated group showed abundant fibroblast cells in the dermis and subcutaneous tissue. The scab fell off earlier in the hydrogel-treated group than it did in the untreated group (Figure 8a). Furthermore, epithelialization at wound sites increased in the hydrogel-treated group, as manifested by marked thickening of the new epidermis. According to reports in the literature, between 3 to 10 days following treatment, re-epithelialization begins from the margin of wounds and moves towards the center of the wound site [5]. At the end of the study (day 14), the least re-epithelialization was observed in the untreated group. The epidermis showed ulcerated areas that were covered with acute inflammatory exudate and infiltration of neutrophils, and a loss of skin adnexa was observed at the burn sites. Active fibroblasts rapidly grew at the wound sites. However, the positive control group showed increased epithelialization. The number of fibroblasts gradually declined as the fibrous composition increased [38]. The hydrogel-treated group showed a higher increase in the formation of keratin and hair follicles, along with the proliferation of blood vessels than the positive control group did. The hydrogel treatment group also showed organized superficial epithelium similar to that of the positive control and was almost completely healed. Increased deposition of collagen was observed in all the groups. The appearance of collagen was clearly observed in the hydrogel-treated group on day 14 (Figure $8 \mathrm{~b}$ ) because of the increased fibroblast proliferation on day 7, which promoted collagen deposition.

Skin wound healing is a complex process with four major phases including hemostasis, inflammation, proliferation, and remodeling. The wound healing process is considered to be enhanced by a moist environment. Our results suggest that hydrogel has the potential to be used as a wound dressing material for partial-thickness burn wounds [5].

\section{CONCLUSION}

Versatile, non-toxic, biodegradable hydrogel microparticles were successfully prepared with BC/AM for use as a wound dressing. The hydrogel microparticles prepared for wound dressing applications showed a highly porous structure and swelling characteristics that were suitable for this purpose. The in vitro assays revealed that the hydrogel microparticles are non-cytotoxic. The in vivo assays suggested that hydrogel promoted faster wound 
healing with no signs of local inflammatory responses. The hydrogel microparticles were biocompatible with the process by promoting re-epithelialization and proliferation of fibroblasts. Therefore, BC hydrogels composed of BC/AM synthesized using microwave irradiation, have the potential to be used for burn wound dressing.

\section{Acknowledgments}

The authors would like to thank the Ministry of Higher Education, Malaysia (UKM-Farmasi-02-FRGS0192-2010) and the Universiti Kebangsaan Malaysia (INOVASI-2013-005) for their financial assistance and support.

\section{Conflicts of interest}

There are no conflicts of interest to declare.

\section{REFERENCES}

(1). Church D, El Sayed S, Reid O, Winston B, Lindsay R. Burn wound infections. Clin. Microbiol. Rev. 2006; 19(2): 403-434.

(2). Mogoşanu GD, Grumezescu AM. Natural and Synthetic Polymers for Wounds and Burns Dressing. Int. J. Pharm. 2014; 463: 127-136.

(3). Pham C, Greenwood J, Cleland H, Woodruff P, Maddern, G. Bioengineered Skin Substitutes for the Management of Burns: a Systematic Review. Burns, 2007; 33: 946-957.

(4). Lootens L, Brusselaers N, Beele H, Monstrey S. Keratinocytes in the Treatment of Severe Burn Injury: an Update. Int. Wound J. 2012; 10: 6-12.

(5). Lin W, Lien C, Yeh H, Yu C, Hsu S. Bacterial cellulose and bacterial cellulose-chitosan membranes for wound dressing applications. Carbohyd. Polym. 2013; 94: 603-611.

(6). Kwak MH, Kim JE, Go J, Koh EK, Song SH, Son HJ, Kim HS, Yun YH, Jung, YJ, Hwang DY. Bacterial cellulose membrane produced by Acetobacter sp. A10 for burn wound dressing applications Carbohyd. Polym. 2015; 122: 387-398.

(7). Huang S, Fu X. Naturally derived materials-based cell and drug delivery systems in skin regeneration. J. Control Release. 2010; 142: 149-159.

(8). Silvestre AJD, Freire CSR, Neto, CP. Do bacterial cellulose membranes have potential in drug-delivery systems? Expert Opin. Drug Deliv. 2014; 11: 1113-1124.

(9). Czaja W, Krystynowicz A, Bielecki S, Brown Jr. RM. Microbial cellulose - the natural power to heal wounds. Biomaterials. 2006; 27: 145-151.

(10). Backdahl H. Risberg B, Gatenholm P. Observations on bacterial cellulose tube formation for application as vascular graft. Mater. Sci. Eng. C Mater. Biol. Appl. 2011; 31(1): 14-21.

(11). Hennink WE, Van Nostrum CF. Novel crosslinking methods to design hydrogels. Adv Drug Deliv Rev. 2012; 64: 223-236.

(12). Jovanovic J, Adnadjevic B. Influence of microwave heating on the kinetics of acrylic acid polymerization and crosslinking. J. Appl. Poly. Sci. 2010; 116: 55-63. 
(13). Zhao Z, Zhong L, Qibin X, Hongxia X, Yuesheng L. Fast synthesis of temperature-sensitive PNIPAAm hydrogels by microwave irradiation. Eur. Poly. J. 2008; 44: 1217-1224.

(14). Pandey M, Mohamad N, Amin MCIM. Bacterial cellulose/acrylamide pH-sensitive smart hydrogel: development, characterization, and toxicity studies in ICR Mice model. Mol. Pharmaceutics 2014; 11: 3596-3608.

(15). Amin MCIM, Abadi AG, Katas H. Purification, characterization and comparative studies of spray-dried bacterial cellulose microparticles. Carbohyd. Polym. 2014; 99: 180-189.

(16). Ahmad N, Amin MCIM, Mahali SM, Ismail I, Chuang VTG. Biocompatible and mucoadhesive bacterial cellulose-g-poly (acrylic acid) hydrogels for oral protein delivery. Mol. Pharmaceutics 2014; 11: $4130-4142$.

(17). Amjad MW, Amin MCI, Katas H, Butt AM. Doxorubicin-loaded cholic acid polyethyleneimine micelles for targeted delivery of antitumor drugs: synthesis, characterization, and evaluation of their in-vitro cytotoxicity. Nanoscale Res. Lett. 2012; 7: 687-789.

(18). Loo Y, Wong Y, Cai EZ, Ang C, Raju A, Lakshmanan A, Koh AG, Zhou, HJ, Lim T, Moochhala SM, Hauser CAE. Ultrashort peptide nanofibrous hydrogels for the acceleration of healing of burn wounds. Biomaterials, 2014; 35: 1-10.

(19). Alsarra IA. Chitosan topical gel formulation in the management of burn wounds. Int. J. Biol. Macromol. 2009; 45: 16-21.

(20). Amin, MCIM, Ahmad N, Halib N, Ahmad I. Synthesis and characterization of thermo and pH responsive bacterial cellulose/acrylic acid hydrogel for drug delivery. Carbohyd. Polym. 2012; 88: 465-73.

(21). Pandey M, Amin MCI, Ahmad N, Abeer MM. Rapid synthesis of superabsorbent smart-swelling bacterial cellulose/acrylamide-based hydrogels for drug delivery. Int. J. Polym. Sci. 2013; 2013: 1-10.

(22). Song Y, Zhou J, Zhang L, Wu X. Homogenous modification of cellulose with acrylamide in $\mathrm{NaOH} / \mathrm{urea}$ aqueous solutions. Carbohyd. Polym. 2008; 73: 18-25.

(23). Marandi GB, Esfandiari K, Biranvand F, Babapour M, Sadeh S, Mahdavinia GR. pH sensitivity and swelling behavior of partially hydrolyzed formaldehyde-crosslinked poly(acrylamide) superabsorbent hydrogels. J. App. Polym. Sci. 2008; 109: 1083-92.

(24). Kumar A, Singh K, Ahuja M. Xanthan-g-poly(acrylamide): Microwave assisted synthesis, characterization and in-vitro release behavior. Carbohyd. Polym. 2009; 76: 261-7.

(25). Sutar, PB, Mishra RK, Pal K, Banthia AK. Development of pH sensitive polyacrylamide grafted pectin hydrogel for controlled drug delivery system. J. Mater. Sci. Mater. Med. 2008; 19: 2247-53.

(26). Vijan V, Kaity S, Biswas S, Isaac J, Ghosh A. Microwave assisted synthesis and characterization of acrylamide grafted gellan, application in drug delivery. Carbohyd. Polym. 2012; 90: 496-506.

(27). Ibrahim M El-S, Mamdouh AM, Abdel AM, Dawidar AM, Hugh DCS. Biodegradable pH-responsive alginate-poly (lactic-co-glycolic acid) nano/micro hydrogel matrices for oral delivery of silymarin. Carbohyd. Polym. 2011; 83: 1345-1354.

(28). Liu X, Tang M, Zhang T, Hu Y, Zhang S, Kong L, Xue Y. Determination of a threshold dose to reduce or eliminate cdte-induced toxicity in 1929 cells by controlling the exposure dose. PLOS ONE. 2013; 8: e59359. doi.org/10.1371/journal.pone.0059359 
(29). Baek HS, Ja YY, Dong WH, Dong HL, Oh-Hun K, Jong-Chul P. Evaluation of the extraction method for

(30). Almeida IF, Pereira T, Silva NHCS. Bacterial cellulose membranes as drug delivery systems: an in vivo skin compatibility study. Eur. J. Pharm. Biopharm. 2014; 106: 264-9.

(31). Muangman P, Opasanon S, Suwanchot S, Thangthed O. Efficiency of microbial cellulose dressing in partialthickness burn wounds. J Am Col Certif Wound Spec. 2011; 27; 3(1): 16-9.

(32). Cai Z, Kim J. Bacterial cellulose/poly(ethylene glycol) composite: characterization and first evaluation of biocompatibility. Cellulose. 2010; 17(1): 83-91.

(33). Anon. Amended final report on the safety assessment of polyacrylamide and acrylamide residues in cosmetics. Int. J. Toxicol. 2005; 2: 21-50.

(34). Boateng JS, Matthews KH, Stevens HNE, Eccleston GM. Wound healing dressings and drug delivery systems: A Review. J. Pharm. Sci. 2008; 97: 2892-2923.

(35). Junker JPE, Kamel RA, Caterson EJ, Eriksson E. Clinical impact upon wound healing and inflammation in moist, wet, and dry environments. Adv. Wound Care 2013; 2: 348-356.

(36). Mohamad N, Amin MCIM, Pandey M, Ahmad N, Rajab N. Bacterial cellulose/acrylic acid hydrogel synthesized via electron beam irradiation: accelerated burn wound healing in an animal model. Carbohyd. Polym. 2014; 114: 312-320.

(37). Tepole AB, Kuhl E. Systems-based approaches toward wound healing. Pediatr. Res. 2013; 73: 553-63.

(38). Chen S, Tsao C, Chang C, Lai Y, Wu M, Chuang C, Chou H, Wang C, Hsieh K. Assessment of reinforced poly(ethylene glycol) chitosan hydrogels as dressings in a mouse skin wound defect model. Mater. Sci. Eng. C, Mater. Biol. Appl. 2013; 33: 2584-2594

\section{Figure legends}

Fig. 1 (a) Comparative Fourier transform infrared (FT-IR) spectra of bacterial cellulose (BC), polyacrylamide (PAM), and hydrogel microparticles (MP), (b) ${ }^{13} \mathrm{C}$ solid-state nuclear magnetic resonance (NMR) spectra of MP (reproduced from (15) with permission from the American Chemical Society, (C) 2014.), (c) X-ray MP.

Fig. 2 Elemental analysis of hydrogel microparticles (MP)

Fig. 3 Surface morphology of (a) oven-dried and (b) freeze-dried microparticles and (c) single freeze-dried microparticle.

Fig. 4 (a) Swelling ratio of hydrogel microparticles at pH 1.5, 5, and 7.4, after 8 and 24 h, (b) cytotoxicity of hydrogel microparticles in mouse fibroblast L929 cells using the extraction and direct contact methods.

Fig. 5 Live/Dead fluorescent images of control and hydrogel-treated cells, where green represents live and red represents dead cells.

Fig. 6 Photographs of wounds treated with hydrogel, positive, and negative controls taken on days $1,3,7$, and 14. 
Fig. 7 Wound closure rate (\%) of burn wound treated with hydrogel, positive control and negative control.

1

Fig. 8 Histopathological observations of the wound healing of test groups on day 1, 7, and 14, (a) with hematoxylin and eosin (H\&E) staining, (b) with Masson's trichrome staining. 


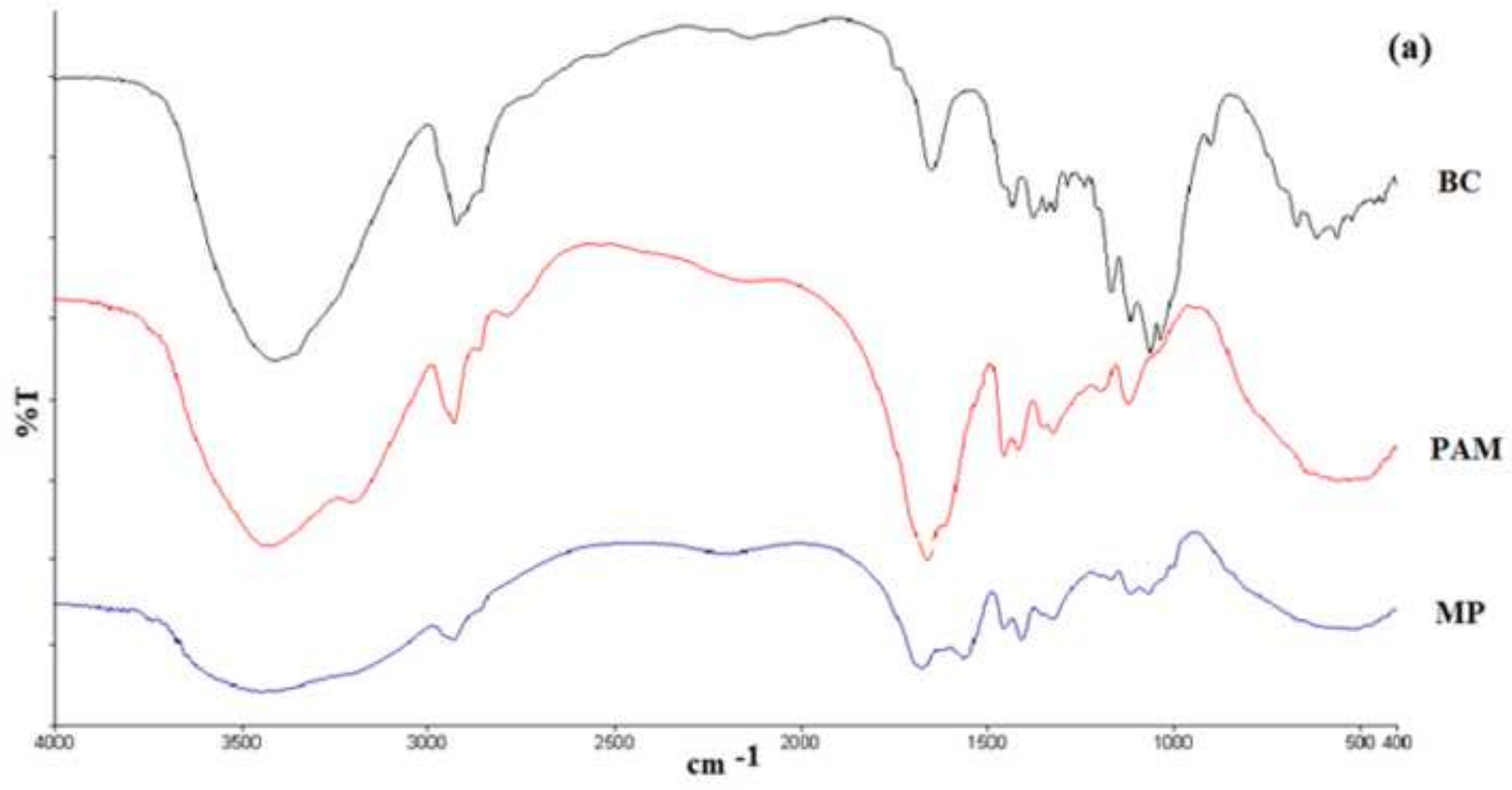




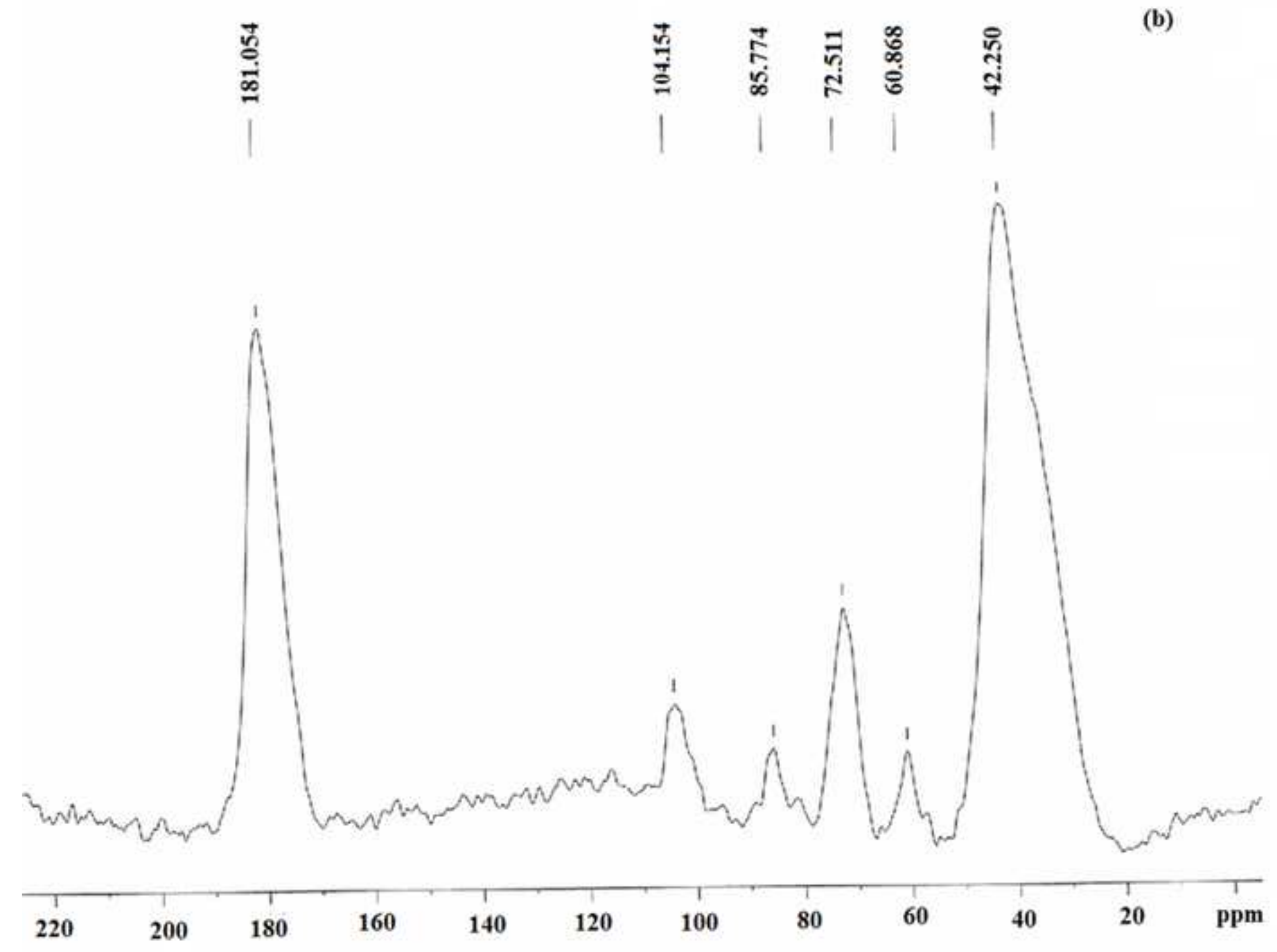




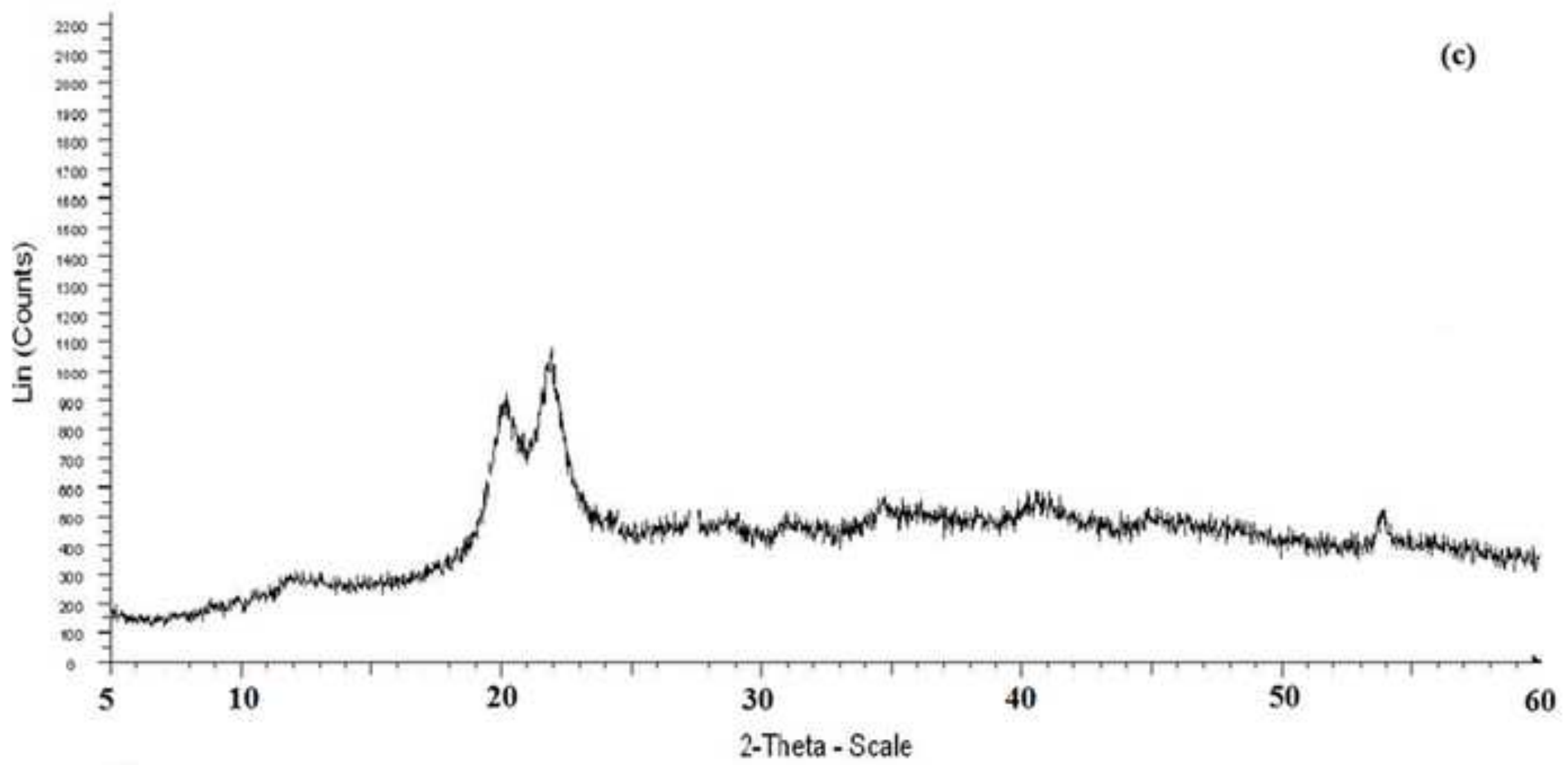




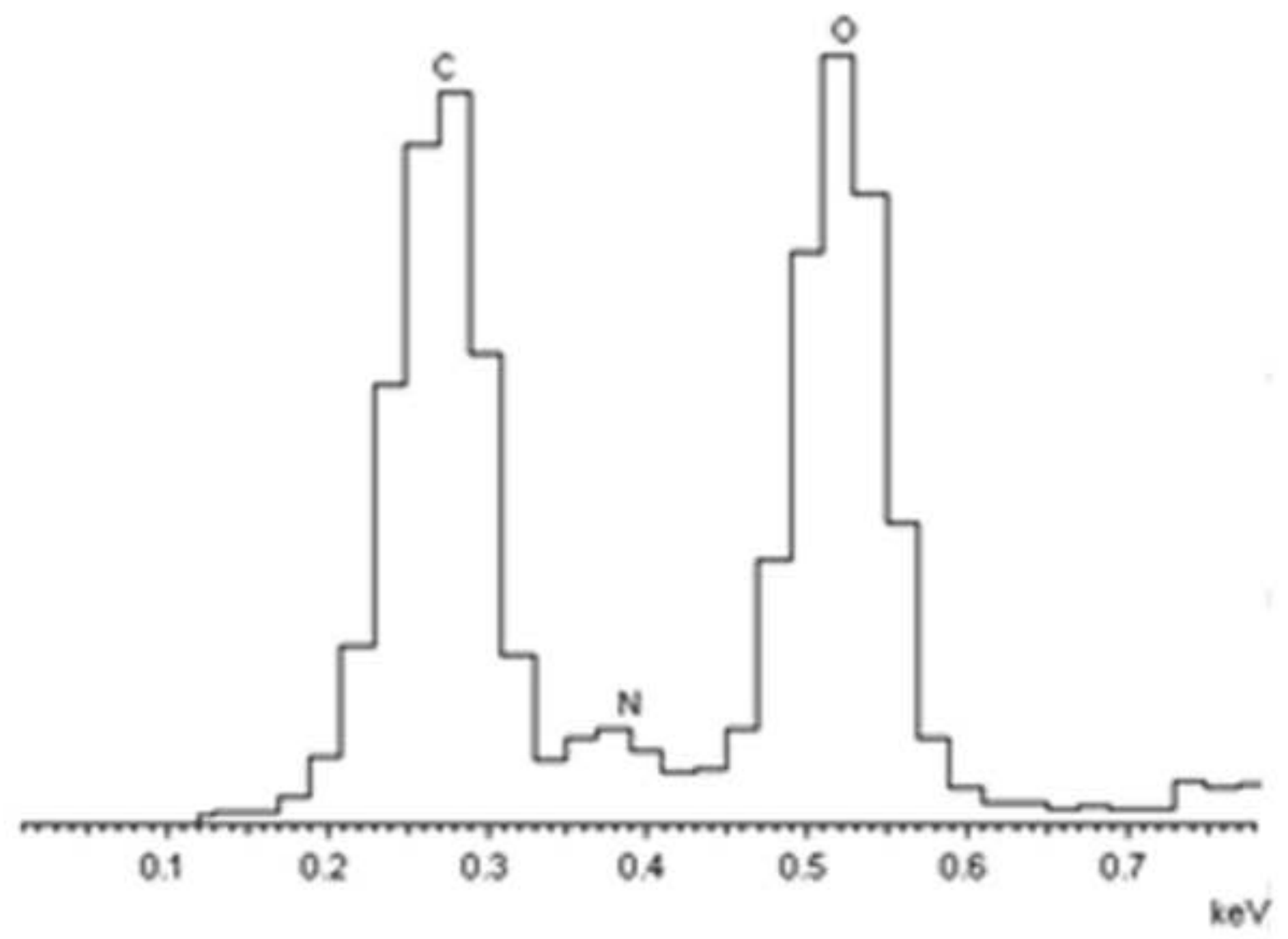



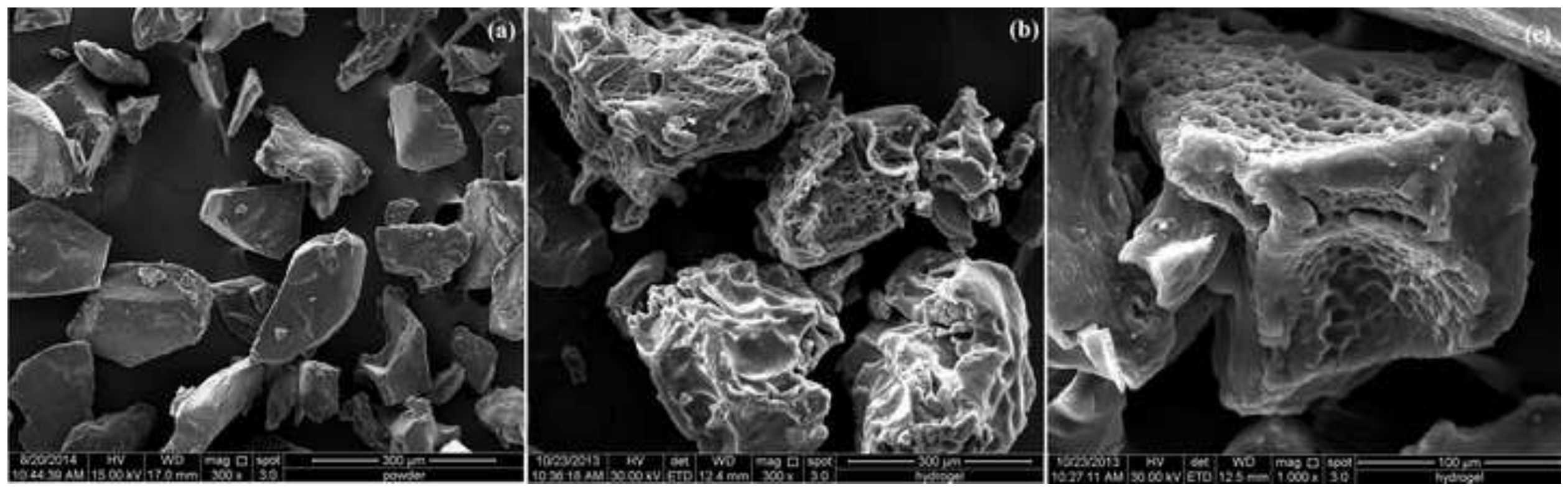


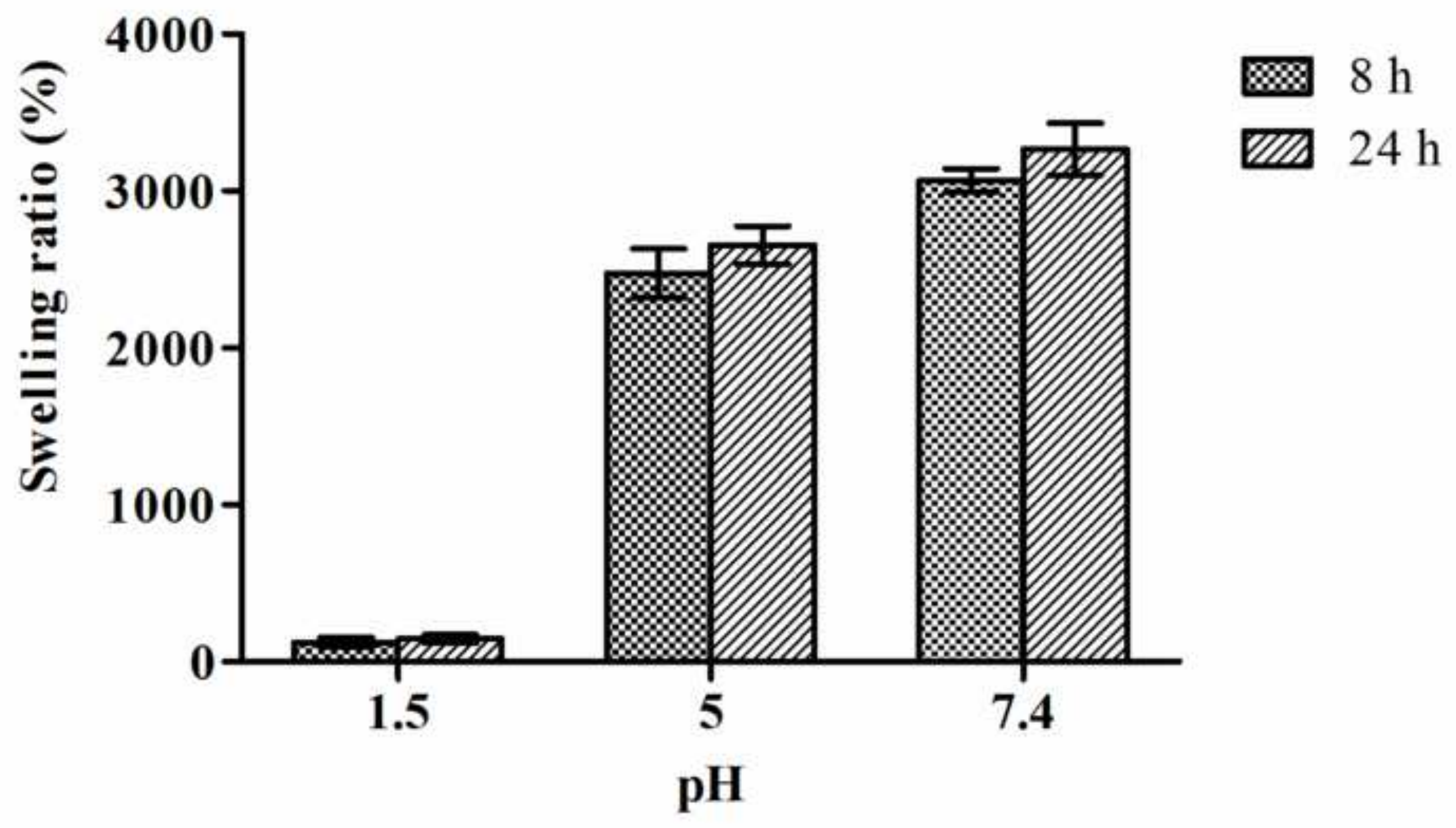




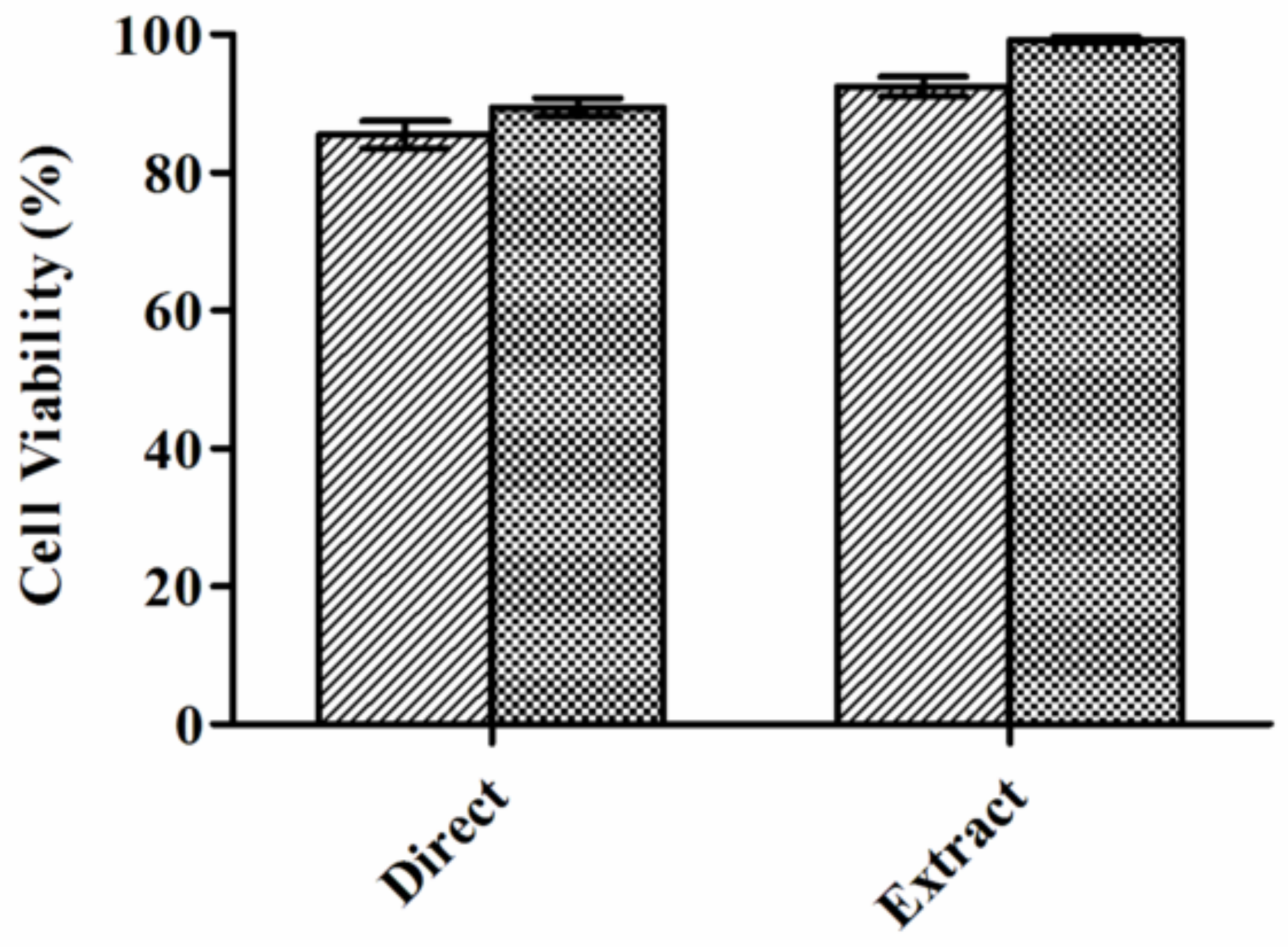


24 h

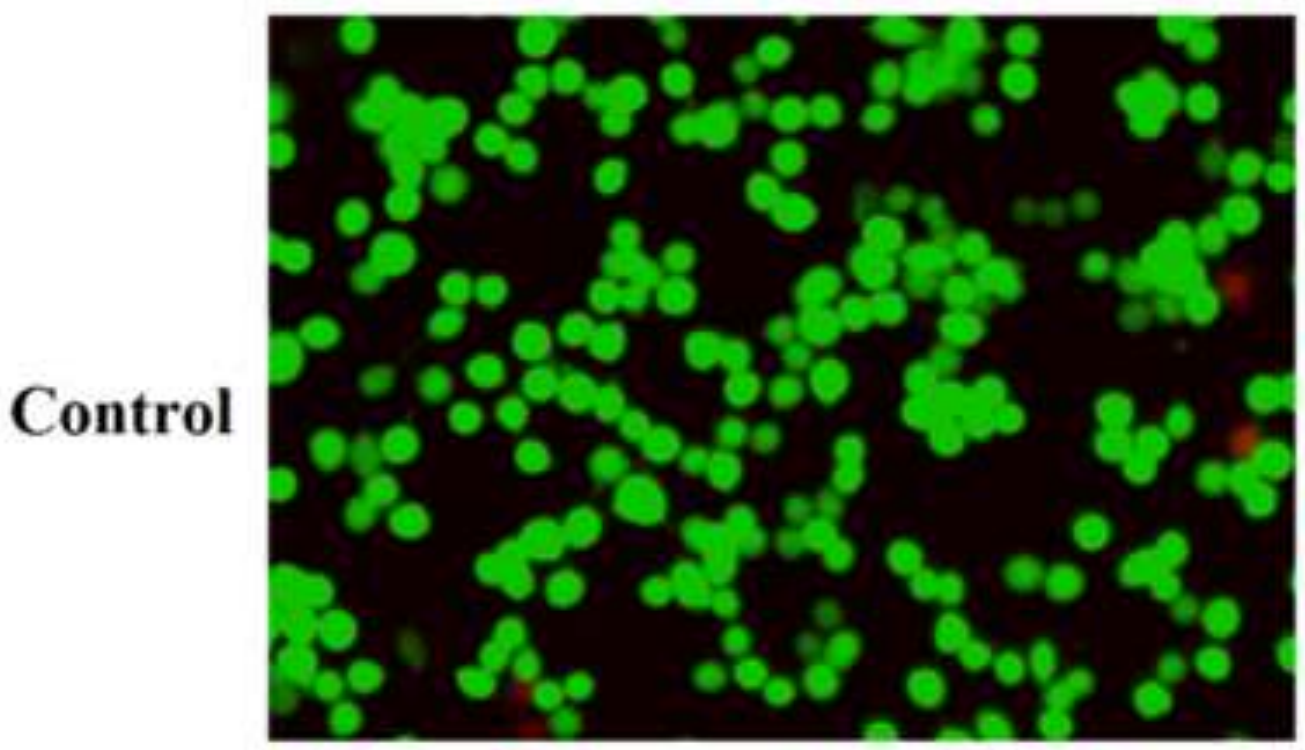

$48 \mathrm{~h}$
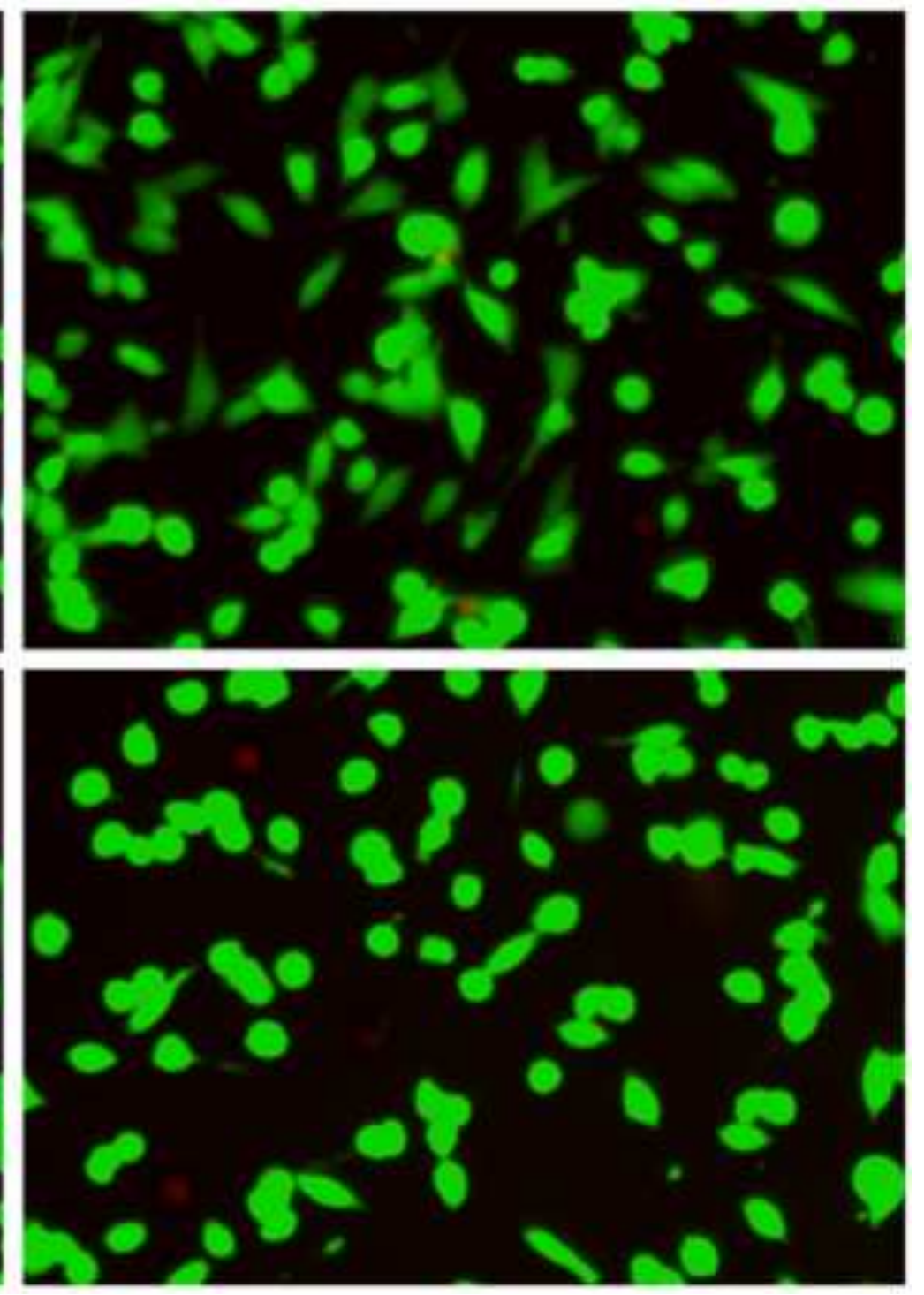

Microparticle treated

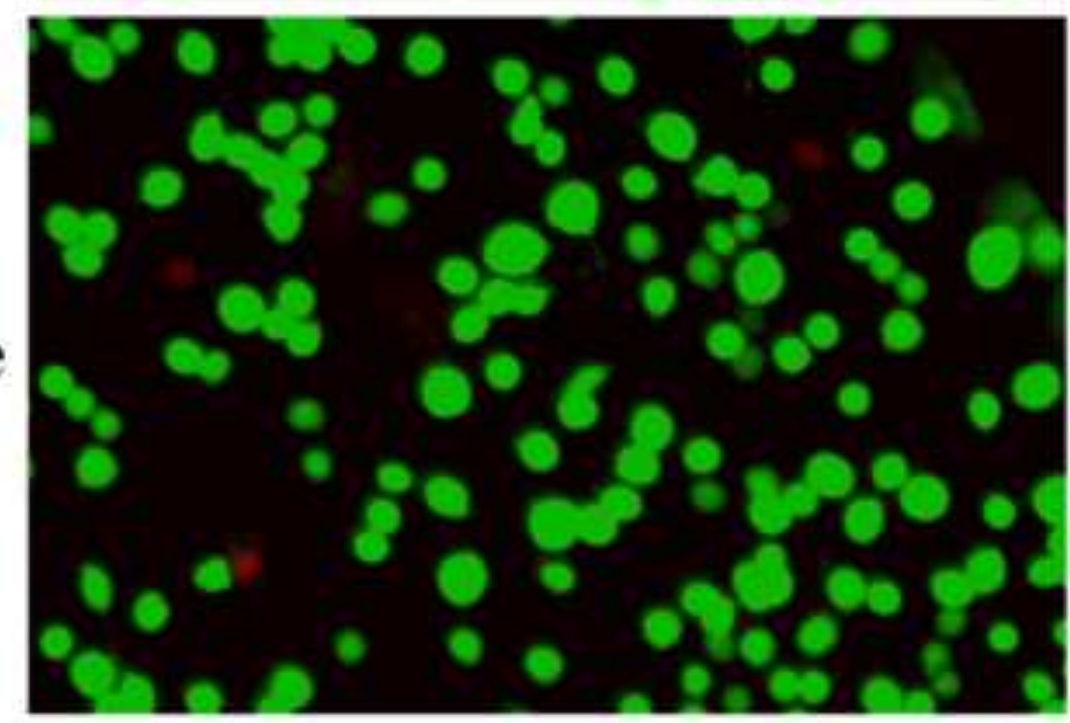

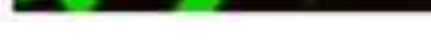



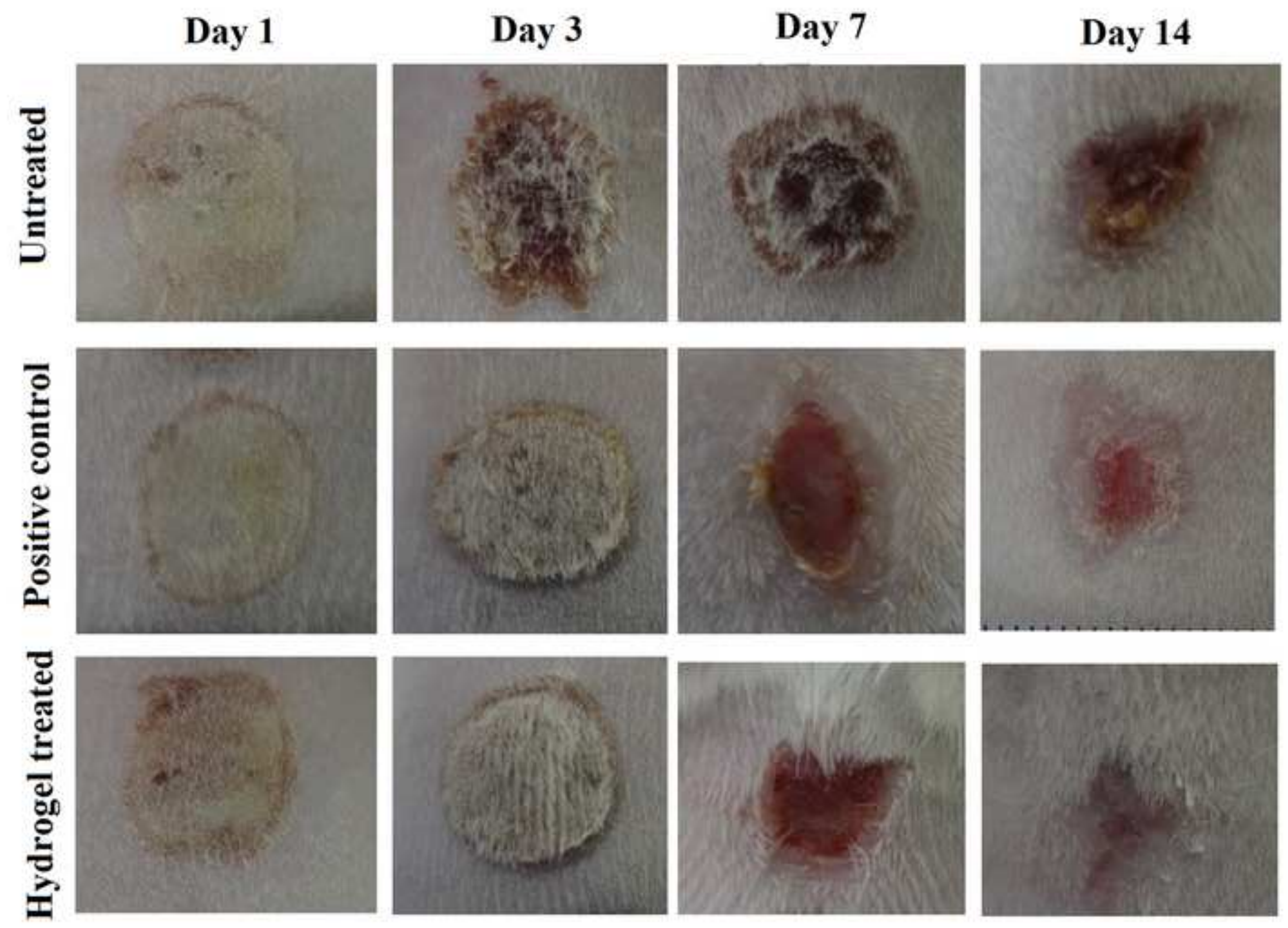


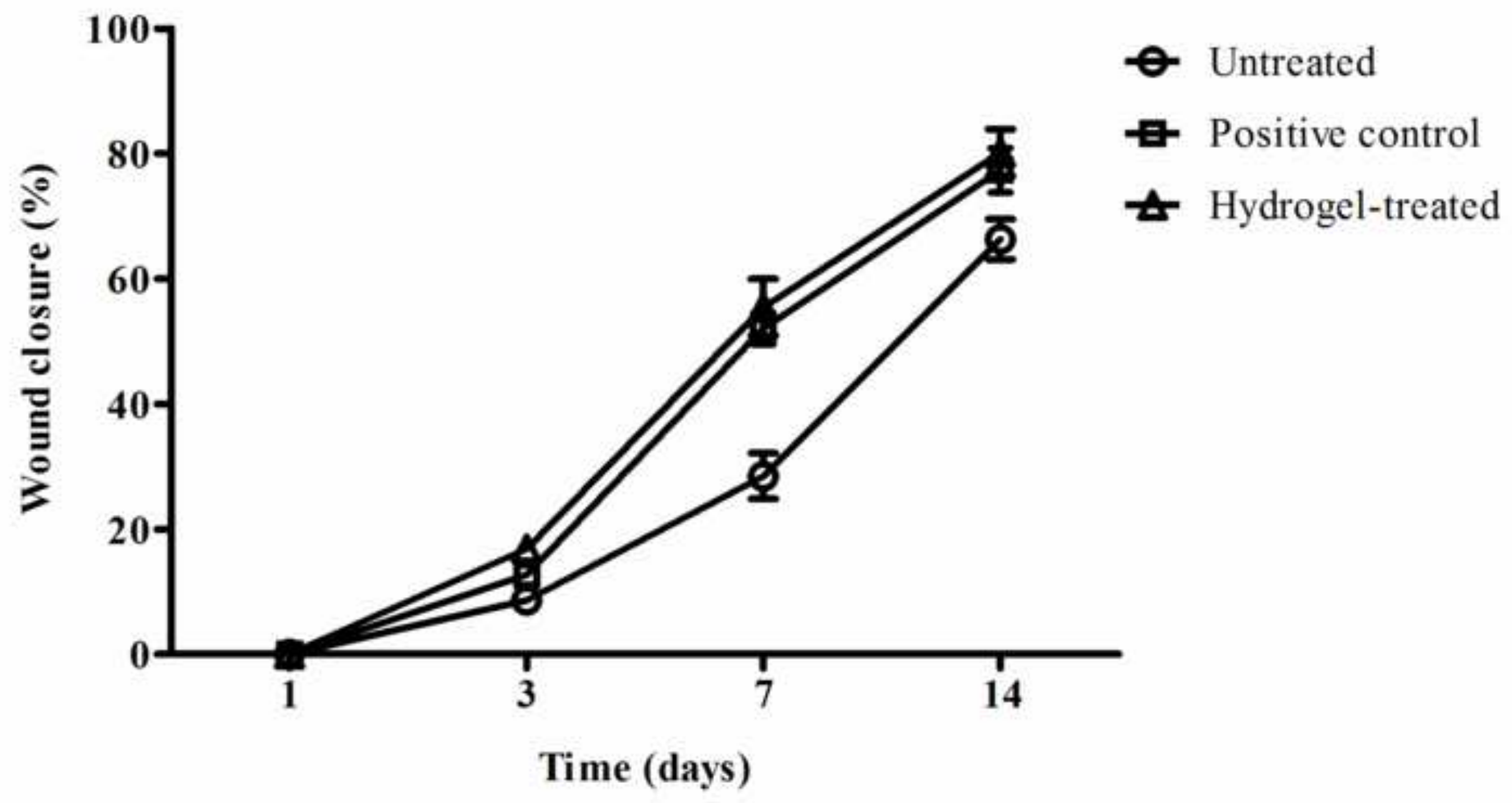




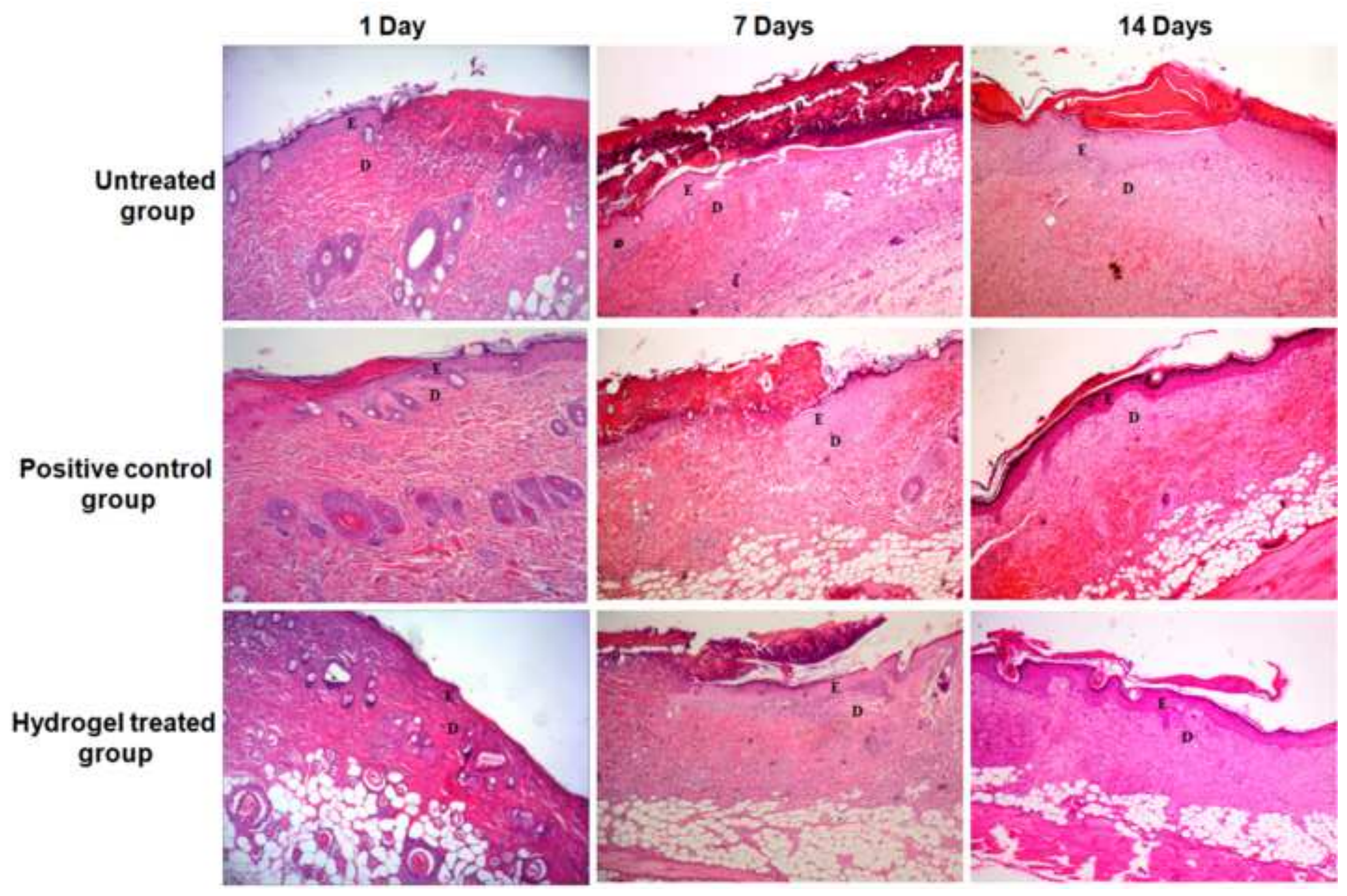




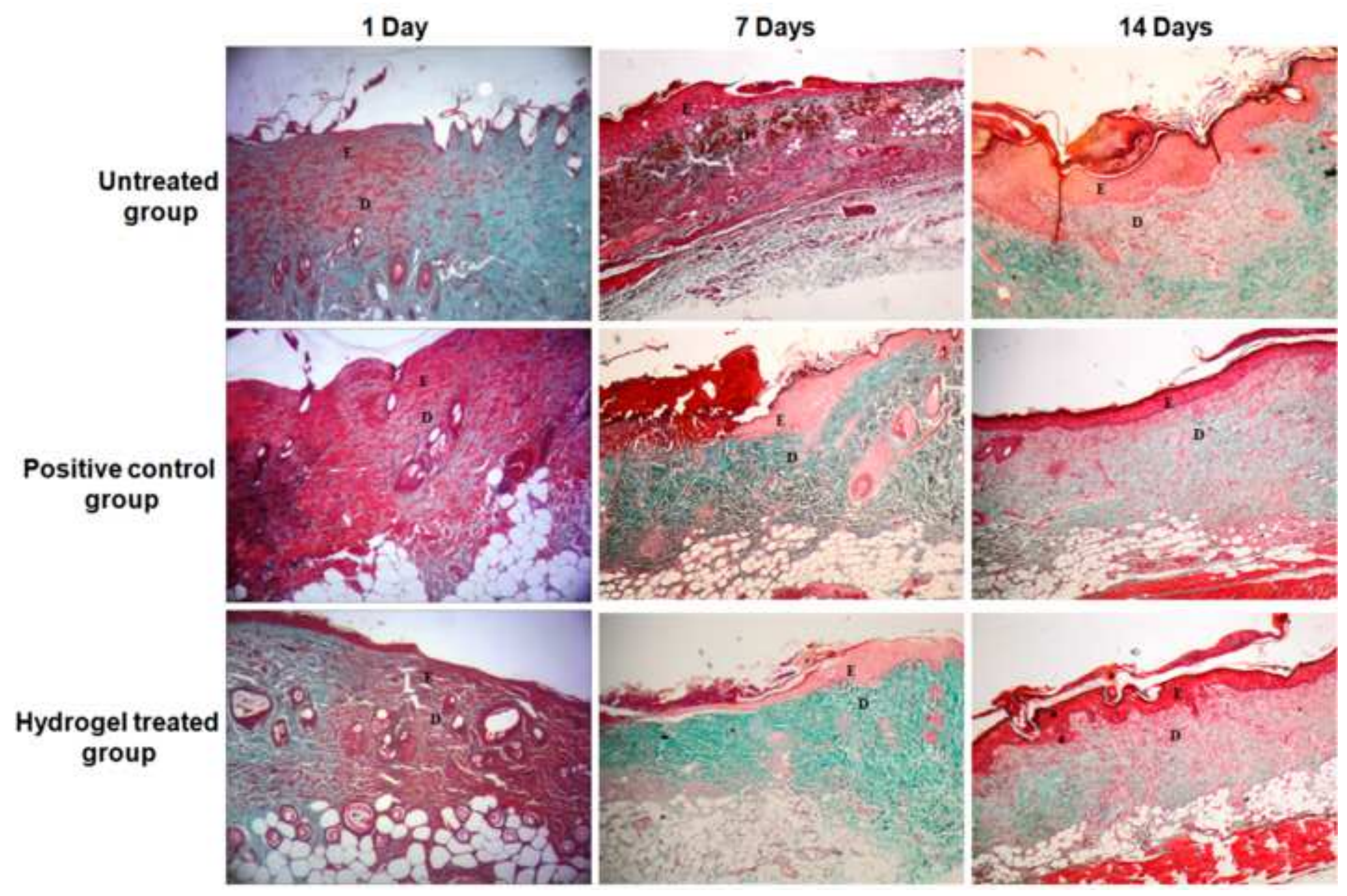


Supplementary Material

Click here to access/download
Supplementary Material

Supplementary Material
\[ \begin{array}{l}\text { Click here to access/download } \\ \text { Supplementary Material }\end{array} \] copy clearance 001.tif 
Click here to access/download

\section{Supplementary Material Appendix .docx}


Click here to access/download Supplementary Material Certificate_of_editing-MDAI_43.pdf 